\title{
Fluorescent particle tracers in surface hydrology: a proof of concept in a semi-natural hillslope
}

\author{
F. Tauro ${ }^{1,2,3}$, S. Grimaldi ${ }^{1,3,4}$, A. Petroselli ${ }^{5}$, M. C. Rulli $^{6}$, and M. Porfiri ${ }^{1}$ \\ ${ }^{1}$ Department of Mechanical and Aerospace Engineering, Polytechnic Institute of New York University, Brooklyn, \\ NY 11201, USA \\ ${ }^{2}$ Dipartimento di Ingegneria Civile, Edile e Ambientale, Sapienza University of Rome, Rome 00184, Italy \\ ${ }^{3}$ Honors Center of Italian Universities, Sapienza University of Rome, Rome 00184, Italy \\ ${ }^{4}$ Dipartimento per l'Innovazione nei Sistemi Biologici, Agroalimentari e Forestali, University of Tuscia, Viterbo 01100, Italy \\ ${ }^{5}$ Dipartimento di Scienze e Tecnologie per l'Agricoltura, le Foreste, la Natura e l'Energia, University of Tuscia, \\ Viterbo 01100, Italy \\ ${ }^{6}$ Dipartimento di Ingegneria Idraulica, Ambientale, Infrastrutture Viarie, Rilevamento, Politecnico di Milano, \\ Milano 20133, Italy
}

Correspondence to: S. Grimaldi (salvatore.grimaldi@unitus.it)

Received: 17 March 2012 - Published in Hydrol. Earth Syst. Sci. Discuss.: 3 April 2012

Revised: 2 August 2012 - Accepted: 3 August 2012 - Published: 24 August 2012

\begin{abstract}
In this paper, a proof of concept experiment is conducted to assess the feasibility of tracing overland flow on an experimental hillslope plot via a novel fluorescent particle tracer. Experiments are performed by using beads of diameters ranging from 75 to $1180 \mu \mathrm{m}$. Particles are sensed through an experimental apparatus comprising a light source and a video acquisition unit. Runoff on the experimental plot is artificially simulated by using a custom-built rainfall system. Particle transits are detected through supervised methodologies requiring the presence of operators and unsupervised procedures based on image analysis techniques. Average flow velocity estimations are executed based on travel time measurements of the particles as they are dragged by the overland flow on the hillslope. Velocities are compared to flow measurements obtained using rhodamine dye. Experimental findings demonstrate the potential of the methodology for understanding overland flow dynamics in complex natural settings. In addition, insights on the optimization of particle size are presented based on the visibility of the beads and their accuracy in flow tracing.
\end{abstract}

\section{Introduction}

Hillslope overland flow controls multiple phenomena in natural watersheds, including surface runoff contributing to the basin hydrologic response (Scherrer et al., 2007; Gomi et al., 2008a; McGuire and McDonnell, 2010; Uchida and Asano, 2010), rill development and erosion mechanics influencing soil roughness (Berger et al., 2010; Ghahramani et al., 2011; Mügler et al., 2011), and pollutant diffusion and nutrient loss affecting agriculture and soil management (Ticehurst et al., 2007).

Major challenges in the implementation of flow measurement systems in hillslopes are due to the ephemeral nature of microchannels along with shallow water depths and high turbidity, the presence of small scale vegetation, and often poor geographical accessibility (Hudson, 2004; Rosso et al., 2007). Overland flow is experimentally monitored by excavating small trenches in hills (Dunjó et al., 2004; Hopp and McDonnell, 2009; Sadeghi et al., 2012; Jost et al., 2012) and collecting samples of water for laboratory or sediment analysis (Budai and Clement, 2011; Vacca et al., 2000; Rulli et al., 2006; Hussein et al., 2007). On the other hand, runoff discharge and flow rate measurements require more invasive procedures, wherein v-notch weirs and gauging flumes are installed in excavated trenches at the borders of experimental 
plots (Domingo et al., 2001; Gomi et al., 2008a,b; Doody et al., 2010; Mayor et al., 2011). Real time flow rate and water stage estimates can be computed by deploying sensors in such flumes, whereas overland flow rate can be automatically recorded by using tipping buckets (Johnson et al., 1996; Fiener and Auerswald, 2005; Léonard et al., 2006; Laloy and Bielders, 2008; Ghahramani et al., 2011). Erosion and runoff experimental studies are also conducted through physical sampling of overland flow water in tapped containers after precipitation events (Mathys et al., 2005; Armand et al., 2009; Patin et al., 2012). Such procedures are highly invasive for the environment and are hardly implemented on large scale plots. In addition, they are not adequate for real-time estimations in micro-channel flows (Tatard et al., 2008).

In overland flow settings, tracing techniques are valid alternatives to stream flow measurement systems, such as water gauging, electromagnetic, and acoustic sensors (Lee et al., 2002; Puleo et al., 2012). In particular, experiments on natural or semi-natural hillslopes are often based on tracers, including chemicals, naturally occurring water isotopes, dyes, and salts (Dunkerley, 2001; Lange et al., 2003; Planchon et al., 2005; McGuire et al., 2007; Berman et al., 2009; McMillan et al., 2012). Tracer dispersion issues and losses are minimized by conducting experiments on small scale plots (Tatard et al., 2008; Li, 2009; Mügler et al., 2011). Nonetheless, the tracer detection requires the deployment of probes or the collection of water samples, which can be hampered by the exiguous depths of natural rills (Tatard et al., 2008; Gomi et al., 2008b).

Interestingly, novel sensing instruments are recently being proposed for overland flow rate estimates. Specifically, in Dunkerley (2003) spot measurements of surface flow rates are computed through an optical device exploiting reflectivity of floating objects. In Qu et al. (2007), a sensor for sediment-laden flow rate is developed to estimate sediment concentration in runoff. Such promising devices provide local information on overland flows, yet their implementation is restricted to small scale and supervised experimental plots due to their limited resilience. In Legout et al. (2012), large scale particle image velocimetry (LSPIV) is coupled with laser scanning to estimate overland flow velocity and experimental results are compared against both hot film anemometry and salt tracing. This comparison suggests that LSPIV is a less invasive approach, which can also be easily automated (Muste et al., 2008). Nonetheless, techniques based on image analysis are affected by ambient illumination, presence of patterns on the water surface (Muste et al., 2011; Jodeau et al., 2008), and image distortions (LeCoz et al., 2010), which pose severe challenges in their implementation in uplands environments.

In this paper, a novel tracing methodology based on the deployment and observation of enhanced fluorescence particles for surface flow measurements is proposed. Such an approach aims at mitigating practical limitations of traditional techniques for monitoring overland flows. Specifically, the insolubility of the particles minimizes tracer adhesion to natural substrates and, therefore, is expected to reduce the requisite quantity of tracing material as compared to liquid dyes. Further, the enhanced visibility of the fluorescent particles allows for non-intrusively detecting the tracer through imaging techniques without deploying bulky probes and samplers in the water. These features along with the use of basic and resilient equipment provide grounding for applying the proposed methodology in an ample spectrum of scenarios, such as ephemeral micro-channels, high-sediment load flows, and heavy floods.

The feasibility of using buoyant fluorescent particles in static and dynamic water conditions in both daylight and dark is demonstrated in Tauro et al. $(2010,2012 b)$ for laboratory settings. The transition of the methodology to natural environments is addressed through a proof of concept experiment performed in the Rio Cordon stream in the Italian Alps (Tauro et al., 2012a). This study mainly assesses the performance of the particles in stream flow settings, where high velocity regimes, presence of foam, and light reflections pose serious challenges to bead detection. Particles are therein used to conduct flow measurements at a stream crosssection and travel time experiments in stream reaches of up to $30 \mathrm{~m}$. Bead diameters of a few millimeters are selected to compensate for high flow rates.

In this paper, the proposed methodology is used for a proof of concept overland flow study on a semi-natural hillslope plot under high turbidity loads and soil and rain drops interaction. Such complex settings require the use of much smaller beads as compared to the stream flow analysis. Therefore, ad-hoc experiments are performed to assess the visibility and detectability of the particle tracers in these severe environmental conditions and their feasibility in estimating overland flow velocities. Experiments are conducted by using particles of varying diameters ranging from 75 to $1180 \mu \mathrm{m}$. The particle detection system, placed across a natural rill at the outlet of the studied experimental plot, hosts a light source for exciting the beads' fluorescence and a waterproof digital camera for video acquisition. Videos of beads' transit are processed through both supervised and unsupervised techniques to estimate average surface velocities of water flowing in the rill.

The rest of the paper is organized as follows. In Sect. 2, the following elements are technically elucidated: the particle tracer and the in house-built experimental detection system; the experimental site including the plot preparation; the image-based analysis procedures used for data processing; and the rainfall simulator. Moreover, in Sect. 2, a detailed description of the experimental procedures is presented. In Sects. 3 and 4, results and comments on experimental findings are reported. Conclusions and remarks are presented in Sect. 5 . 


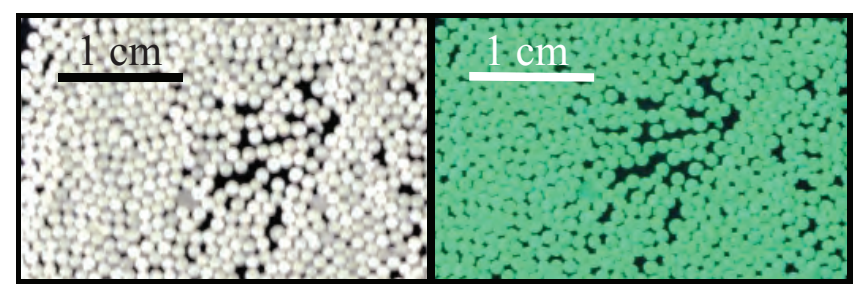

Fig. 1. Left, view of a $0.8 \mathrm{~mm}$ sample of off-the-shelf fluorescent particles under daylight, and right, under $365 \mathrm{~nm}$ UV light.

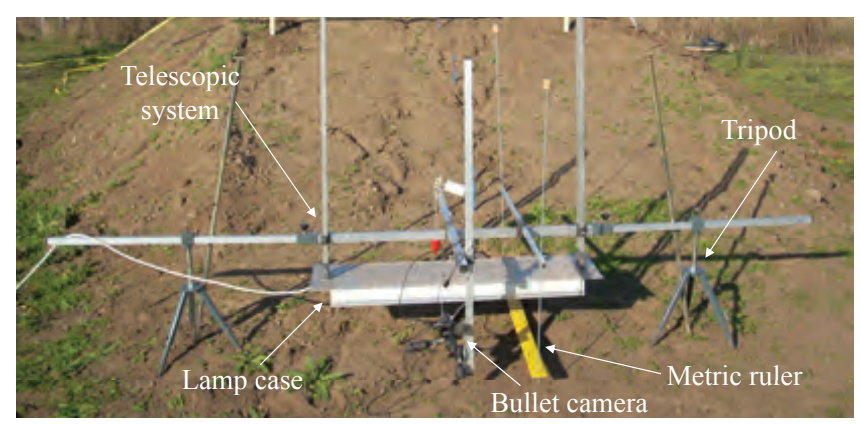

Fig. 2. Experimental apparatus including the light source and the video acquisition units. The metric ruler is used for calibrating acquired videos.

\section{Materials and methods}

\subsection{Fluorescent particle tracer apparatus}

The buoyant fluorescent particles used in this study are purchased from Cospheric LLC (http: //www.cospheric-microspheres.com). The spheres are white under daylight and emit yellow-green light $(561 \mathrm{~nm}$ wavelength) if excited by a UV light source ( $365 \mathrm{~nm}$ wavelength), see Fig. 1. The particles are made of polyethylene and their fluorophore is embedded in the polymer matrix which allows for a long luminescence lifetime and enhanced and uniform visibility. The spheres are slightly buoyant and their nominal dry density is $0.98 \mathrm{~g} \mathrm{~cm}^{-3}$. Table 1 indicates the classes of particles used in this proof of concept experiment ordered in terms of their diameter. This wide spectrum of diameters is used to establish guidelines for particle selection in tracing shallow waters in natural conditions.

Particles' transits are recorded as the beads float on the rill water surface underneath the experimental detection apparatus. The apparatus hosts both light source and video acquisition units, see Fig. 2.

A telescopic system of vertical aluminum bars is connected to the lamp case and allows for regulating image illumination by adjusting the distance of the light source from the water surface. The case contains an array of $14 \mathrm{UV} 8 \mathrm{~W}$ lamps in parallel and series connections. A low cost water proof Bullet HD 1080p camera is located on a tripod head connected to a vertical aluminum bar. The Bullet camera is

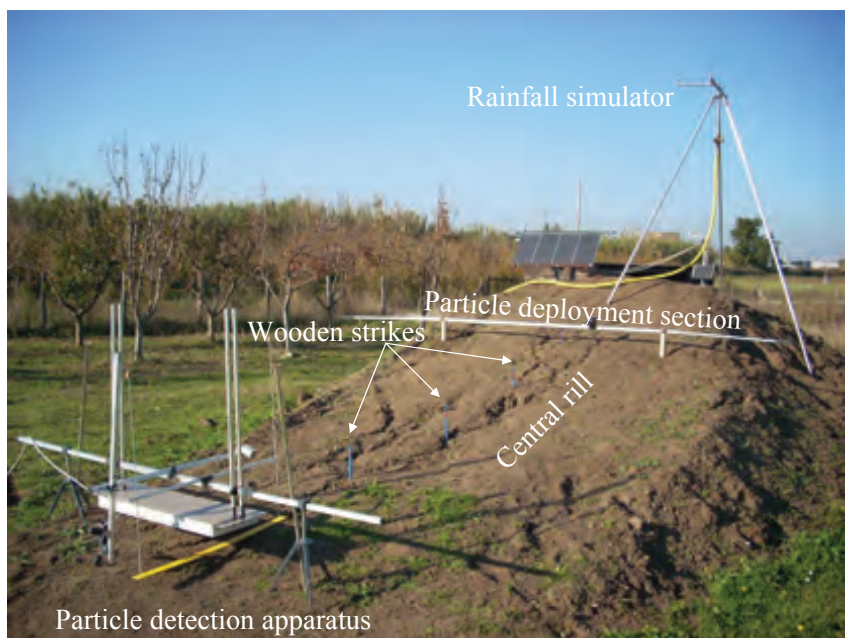

Fig. 3. View of the experimental site depicting the particle detection apparatus and the rainfall simulator.

manually operated and set at $1920 \times 1080$ pixels resolution for video recording at the acquisition frequency of $30 \mathrm{~Hz}$. A compensating counterbalance is used to adjust the distance of the camera from the surface of interest. A metric ruler installed on aluminum rods allows for calibration of the acquired videos. The distance of the video acquisition unit from the surface and light source can be adjusted according to illumination and dimensions of the field of view. In dim illumination conditions, a $568 \mathrm{~nm}$ optical filter is placed on the bullet camera to emphasize particle brightness.

\subsection{Experimental site}

Experiments are performed in a terrain parcel in the Azienda Agraria at the University of Tuscia, Viterbo, Italy, where a semi-natural hillslope is prepared out of $40 \mathrm{~m}^{3}$ of soil, see Fig. 3. The plot is $1.7 \mathrm{~m}$ high, $6.5 \mathrm{~m}$ long, and $3 \mathrm{~m}$ wide and it is covered by grass only for $10 \%$. The granulometry of the soil is provided in Table 2 .

In the center of the plot a mild concavity is preliminarily raked to create a preferential path to rainfall and then irrigated for a few hours. After irrigation, a $4 \mathrm{~m}$ long central rill is formed in the plot and the experimental detection apparatus is located at its terminal part, see Fig. 3. The slope of the hill is approximately equal to $17^{\circ}$ and shows a slight concavity after a few rainfall experiments. A rainfall simulator is placed on the top corner of the plot, see Fig. 3, to provide a uniform rain distribution on the entire hill. The particle deployment section is marked with wood strikes at approximately $4 \mathrm{~m}$ upstream from the detection setup. Four additional wood strikes are installed one meter apart along the rill from the upstream section. 
Table 1. Classes of particle diameters used for the experiments.

\begin{tabular}{cccccccccc}
\hline Class & 1 & 2 & 3 & 4 & 5 & 6 & 7 & 8 & 9 \\
\hline Diameter $(\mu \mathrm{m})$ & $75-90$ & $106-125$ & $150-180$ & $250-300$ & $355-425$ & $500-600$ & $710-850$ & $850-1000$ & $1000-1180$ \\
\hline
\end{tabular}

Table 2. Granulometry of the experimental plot. The soil used for the plot can be classified as sand according to the International Society of Soil Science (ISSS).

\begin{tabular}{cccc}
\hline Soil type & Clay & Silt & Sand \\
\hline Portion $(\%)$ & 11.55 & 21.76 & 66.69 \\
\hline
\end{tabular}

\subsection{Particle detection procedure}

Travel time experiments are conducted by synchronizing particle deployment and video acquisition. Particle travel time is identified as the time the beads take to flow from the deployment section on the plot to the detection apparatus along the $4 \mathrm{~m}$ long rill. The arrival of the particles at the detection setup refers to when the particles enter the field of view of the camera. The transit of the particles is identified through image-based analysis tools by converting captured videos into RGB frames and then analyzing the sole green channel where particle emissions are more evident. In particular, gray-scale frames are processed by using a modified version of the following index $\mathcal{G}$ defined by Tauro et al. (2010):

$\mathcal{G}=\frac{\sum_{i \in \mathcal{I}}\left(c_{i}\right)^{\alpha} n_{i}}{\sum_{i \in \mathcal{I}} n_{i}}, \mathcal{I}=\left\{i \in\{0,1, \ldots, 255\}: n_{i}>0\right\}$,

with $n_{i}=n_{i}^{\mathrm{p}}-n_{i}^{\mathrm{b}}$. Here, $n_{i}^{\mathrm{b}}$ and $n_{i}^{\mathrm{p}}$ refer to the pixel count for the background and particle images, respectively. The term $c_{i}$ represents the pixel intensity classes from 0 to 255 where the power $\alpha$ is introduced to assign a higher statistical weight to the exiguous number of bright pixels in the entire image corresponding to the particles. In particular, the exponent $\alpha$ is set to 10 throughout the whole set of experiments to emphasize brighter pixels against the background. The relatively high value of the exponent is motivated by the particularly adverse illumination and environmental conditions. It is found by performing a preliminary analysis on a single video where the value of the exponent is varied until eventual peaks in the index are clearly identified. It is noted that background images are obtained from the original ones by applying a bottom-hat transformation, (Haralick et al., 1987; Gonzalez et al., 2004). Peaks in the index $\mathcal{G}$ correspond to sequences of frames where brightness is maximized and therefore where the particles are more likely to be (Tauro et al., 2010).

An automatic procedure for the identification of the beads is introduced to partially filter signal noise due to the

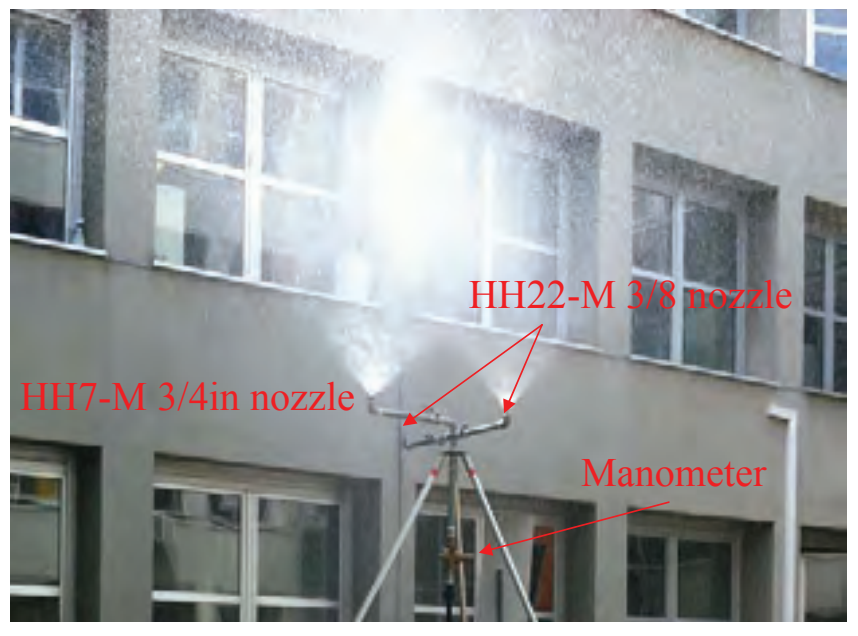

Fig. 4. View of the rainfall simulator. Water jets are sprayed from two HH22-M 3/8 in and one HH7-M 3/4 in nozzles.

presence of external and uncontrolled light sources, water surface reflections, and extraneous objects and sediments. Specifically, a moving average of the time trace of the index is computed for each experimental video by using subsets of ten consecutive images. For convenience, such filtered time trace is referred to as $G$. Then, peaks in the signal are automatically detected by fitting $G$ with a gaussian function. This fit is first implemented using windows of 50 values of the filtered time history. In the fitting procedure, the length of the fitted window is iteratively increased up to 150 values to capture eventual occurrences of elongated particle trains. Fitting is executed by constantly skipping 15 values of the filtered time trace. The nonlinear least square method is used to perform the fitting. Goodness of the procedure is ascertained by imposing that the coefficient of determination is equal or greater than a threshold value equal to 0.85 .

The sequence of frames identifying the transit of the particles are found by imposing further constraints on the fitted window which presents the highest coefficient of determination. In particular, the mean value of the fitting gaussian function is required to lay in the interval $[m-0.15 l, m+0.15 l]$, where $m$ is the mean time in the window of interest and $l$ corresponds to the length of the window. In addition, constraints are imposed on the minimum and maximum values of $G$ in the analyzed window. Specifically, the presence of a peak in the intensity is assessed by imposing $0.4 \leq$ $(\max G-\min G) / \max G \leq 1$ in the fitted interval. Experimental videos satisfying such constraints lead to the identification of particle transits. As the brightest frame sequences 


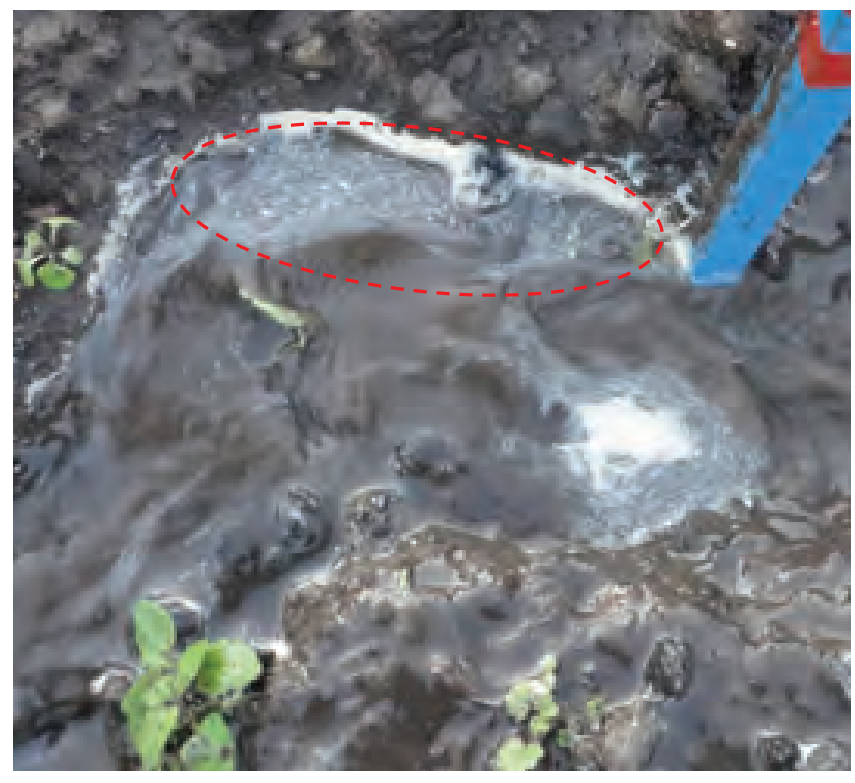

Fig. 5. Beads of smaller diameters trapped at the outside bend of the rill, see red dashed ellipse.

are determined, the frame order number corresponding to the first value of $G$ in the fitted window is divided by the camera acquisition frequency and used to calculate the beads travel time.

\subsection{Rainfall simulator}

The plot rainfall system consists of a pressurized nozzle rainfall simulator (Esteves et al., 2000; Pérez-Latorre et al., 2010). The simulator is designed and developed at the Politecnico di Milano based on the prototype by Riley and Hancock (1997). The basic structure of the simulator comprises a telescopic aluminum tripod connected to a steel plate. Three hoses are riveted to the plate and water is sprayed through a system of three nozzles as displayed in Fig. 4.

Specifically, a HH7-M 3/4 in nozzle is mounted on the central hose, whereas two smaller HH22-M 3/8 in nozzles are placed onto the lateral hoses. Three cut-off valves allow for selectively activating the nozzles and controlling rainfall intensity. Water is supplied to the hoses through a plastic reinforced tube connected to the steel plate through a sleeve coupling. Rainfall intensity is regulated by using a pressure gauge. Water is jetted from an height of approximately $2.7 \mathrm{~m}$ from the ground and can homogeneously cover an area of approximately $5 \times 5 \mathrm{~m}^{2}$. Rainfall intensities can be varied from a minimum of $40 \mathrm{~mm} \mathrm{~h}^{-1}$ by using the two smaller nozzles to $140 \mathrm{~mm} \mathrm{~h}^{-1}$ by operating the three nozzles simultaneously.

\subsection{Experiment description}

Travel time experiments are conducted by activating the rainfall simulator at the constant intensity of approximately
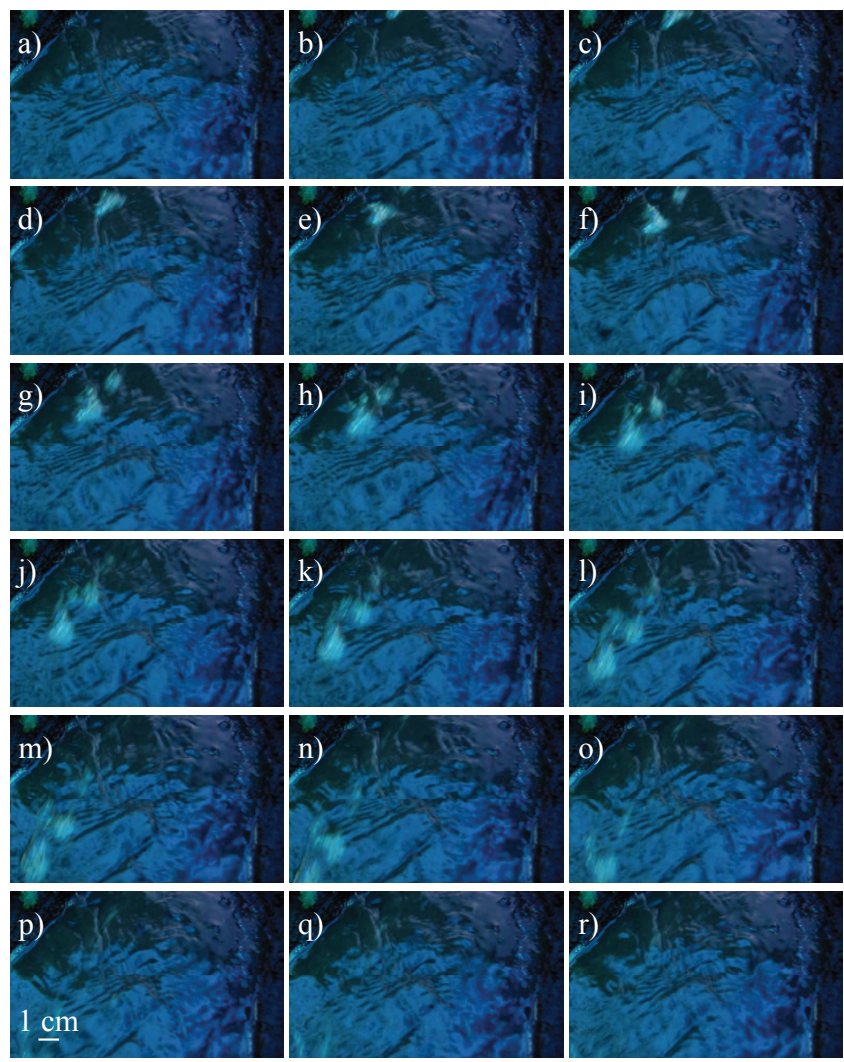

Fig. 6. Sequence of snapshots depicting the transit of a cloud of particles flowing in the rill below the detection apparatus. The diameter of the beads lays in the range $75-90 \mu \mathrm{m}$.

$50 \mathrm{~mm} \mathrm{~h}^{-1}$ to produce a water head of a few centimeters in the rill. The particle detection apparatus is placed at the flat base of the hillslope, that is, at the terminal section of the rill with the bullet camera and the lamp unit at approximately $20 \mathrm{~cm}$ from the rill bed. To prevent excessive distortion in the videos, the camera is angled at $70^{\circ}$ from the horizontal. The simulator nozzles are placed at an height of approximately $2.3 \mathrm{~m}$ from the soil on the top of the hillslope.

For each experiment, a sample of 4-5 $\mathrm{g}$ of particles of a selected diameter class is deployed at the rill onset at approximately $4 \mathrm{~m}$ from the detection apparatus. The instant of deployment and the beginning of the video are synchronized with a precision of approximately $0.1 \mathrm{~s}$. Such precision is achieved by using a chronometer synchronized with the camera. For each class of particle diameters, ten repetitions are performed. The rainfall simulator is active for the entire duration of the experiments. Once videos are taken, frames are processed to estimate surface flow velocity by dividing the total length of the rill by the particle travel time.

Before and after each experiment, the width and depth of the rill at the strikes' sections and underneath the detection apparatus are measured to account for erosion and sediment transport phenomena and to monitor rill bed evolution. In addition, experiments are performed over one month and during 


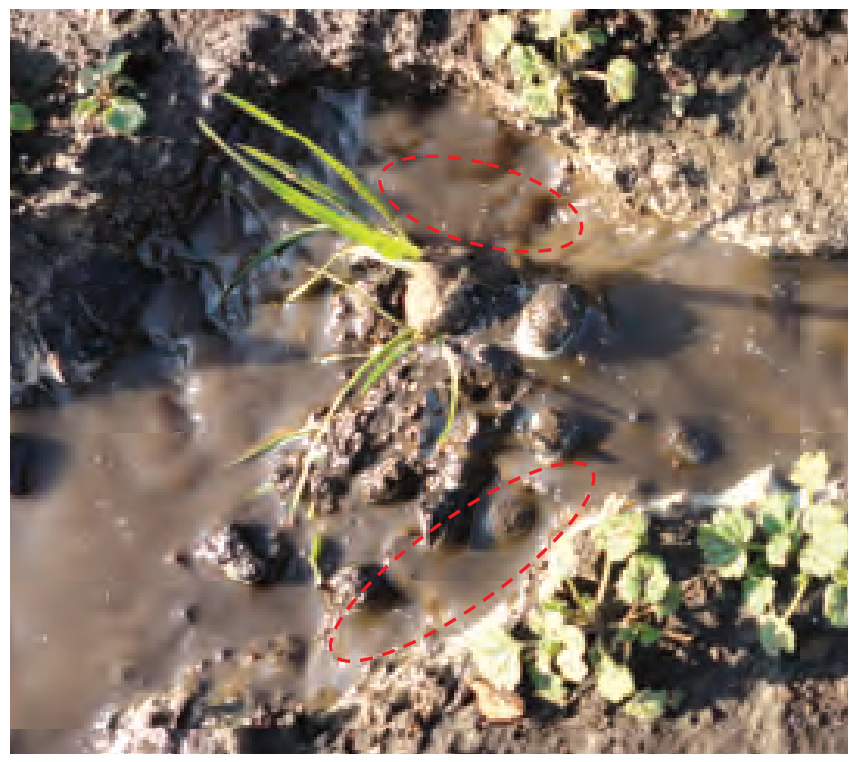

Fig. 7. Beads of larger diameters diffuse in the channel due to the presence of sediments and subrills, see red dashed ellipses.

sunny days in absence of strong wind to limit possible biases in the uniformity of the simulated rainfall. To prevent destructive rill bed erosion and sediment wash-off, the plot is covered with a waterproof cloth during rainy days.

\section{Results}

\subsection{Supervised analysis}

Ten videos for each class of bead diameters are converted to frames and manually analyzed to observe the transit of the particles. This supervised visual analysis demonstrates the enhanced detectability of the fluorescent particles in complex conditions. Specifically, particles from all classes are generally visible in the area captured by the camera despite poor image quality.

Three different behaviors can be observed by visually analyzing recorded videos according to the specific dimensions of the particle tracer. For particles of diameters ranging from 75 to $180 \mu \mathrm{m}$, deployed samples appear as a white powder as they flow along the rill, see Fig. 5, where beads are trapped at the rill outside bend into small vortical structures. Particles are then released downstream from the bend that are visible in the detection section depending on the size of the bead cloud.

Figure 6 displays the transit of a cloud of 75-90 $\mu \mathrm{m}$ beads as captured by the camera. The powder crosses the region of interest, that extends for approximately $8 \mathrm{~cm}$, in 18 frames. Note that snapshots in Fig. 6 are not orthorectified. Therein, the particle cloud compactly travels throughout the entire length of the region of interest making the beads easily detectable by the operator. In addition, fluorescence is clearly
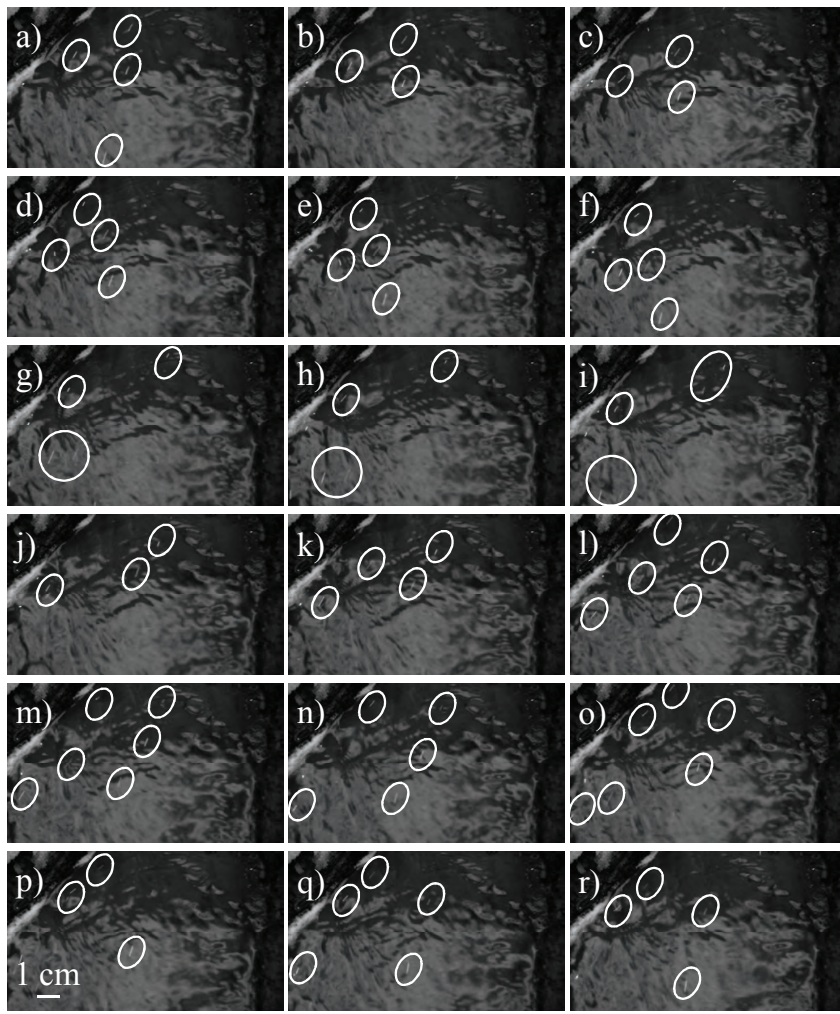

Fig. 8. Sequence of snapshots depicting the transit of single particles flowing in the rill below the detection apparatus. Diameters of the beads are in the range $1000-1180 \mu \mathrm{m}$. Only the green channel is reported for clarity.

recognizable against the background even though water turbidity and suspended sediment load are remarkable.

Conversely, particles ranging from 710 to $1180 \mu \mathrm{m}$ tend to disperse as they are deployed in the rill, see Fig. 7, where particles of larger diameters disperse due to the presence of sediments and subrills. The samples travel in the form of isolated particles that are still visible at the detection section due to their relatively large size.

In particular, Fig. 8 displays the transit of isolated particles of $1000-1180 \mu \mathrm{m}$ in diameter. In this case, the particle train is highly elongated and its entire passage is difficult to identify. Specifically, the transit of the sample is detected as a sequence of independent particles in the camera field of view.

Particles of intermediate sizes, that is, beads ranging from 250 to $600 \mu \mathrm{m}$, are affected by a combination of the two formerly described behaviors. In particular, dispersal of the sample tends to occur from the very deployment into the rill as for the $710-1180 \mu \mathrm{m}$. On the other hand, such particles are not distinctly visible when reaching the detection apparatus due to their rather small dimensions. These factors critically affect the detection of the particles by visual inspection.

Travel times computed through visual inspection are obtained by identifying the frame where beads first appear in the camera's region. Since the camera acquisition and 


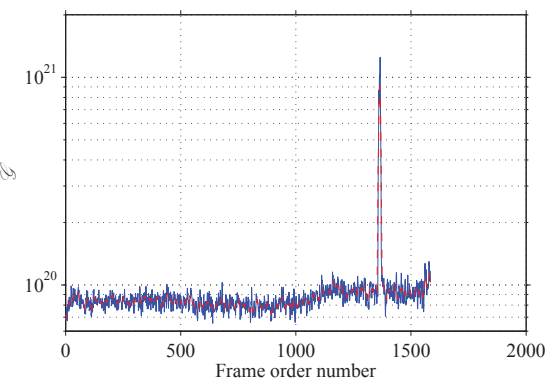

a)

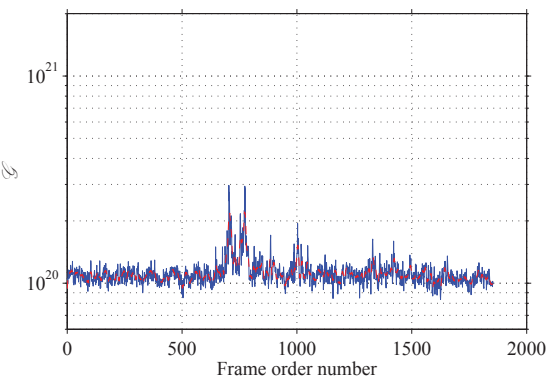

b)

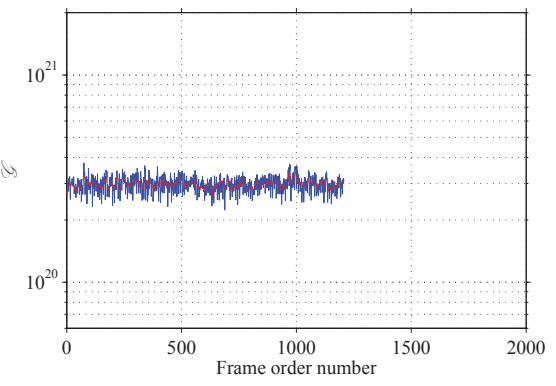

c)

Fig. 9. Index $\mathcal{G}$ as obtained from Eq. (1) for (a) beads of 75-90 $\mu \mathrm{m}$; (b) 1000-1180 $\mu \mathrm{m}$; and (c) 500-600 $\mu \mathrm{m}$. Moving averaged index, $G$, is presented in red.

particle deployment are synchronized, the time taken by the particle to reach the detection apparatus is easily found by dividing the frame order number by the camera acquisition frequency. Velocity is then obtained by dividing the travel time by the approximate length of the rill, that is, $4 \mathrm{~m}$.

Two additional travel time experiments with rhodamine WT dye are conducted to compare the presented methodology with more commonly used approaches. Experiments with rhodamine are conducted by releasing $0.5 \mathrm{ml}$ of dye at the deployment section and by synchronizing the release with the acquisition of the digital camera. The time the dye takes to flow along the $4 \mathrm{~m}$ long rill is found by converting experimental videos into frames and then manually analyzing the images. The first frame at which the presence of the dye is observed is then divided by the acquisition frequency of the digital camera to recover the travel time.

Estimations of the travel time through visual inspection are generally possible for videos depicting transits of the 1000$1180 \mu \mathrm{m}$ particles. In this case, the analysis gives an average velocity of $0.33 \mathrm{~m} \mathrm{~s}^{-1}$ over the ten experimental repetitions with a standard deviation of $0.02 \mathrm{~m} \mathrm{~s}^{-1}$. This value is in good agreement with velocity obtained by using the rhodamine dye, that is, $0.34 \mathrm{~m} \mathrm{~s}^{-1}$ with standard deviation $0.01 \mathrm{~m} \mathrm{~s}^{-1}$. Experiments with smaller particles do not lead to accurate estimations of travel time due to the poor visibility of the first beads arrival.

\subsection{Unsupervised analysis}

The above discussion on particle visibility is supported by the calculation of the index $\mathcal{G}$ and its filtered version $G$ on experimental videos. Specifically, Fig. 9 displays the index $\mathcal{G}$ for three representative experiments for particles of diameters equal to $75-90 \mu \mathrm{m}, 1000-1180 \mu \mathrm{m}$, and $500-600 \mu \mathrm{m}$, respectively. The peak at frame 1366 in Fig. 9a pertains to the passage of the cloud of particles depicted in Fig. 6. Two peaks and higher values of the index are observed from frame 694 to frame 791 in Fig. 9b, relative to the snapshots shown in Fig. 8. On the other hand, in Fig. 9c, no peak is clearly evident. Such findings confirm that the index successfully
Table 3. Velocities obtained through the image analysis procedure, IM Velocity, and visual analysis, VA Velocity. VA velocities are reported for the larger classes of diameters since experiments with smaller particles do not allow for accurate travel time estimations.

\begin{tabular}{ccc}
\hline $\begin{array}{c}\text { Diameter } \\
\mu \mathrm{m}\end{array}$ & $\begin{array}{c}\text { IM Velocity } \\
\mathrm{m} \mathrm{s}^{-1}\end{array}$ & $\begin{array}{c}\text { VA Velocity } \\
\mathrm{m} \mathrm{s}^{-1}\end{array}$ \\
\hline $75-90$ & 0.08 & n.a. \\
& 0.11 & n.a. \\
$150-180$ & 0.11 & n.a. \\
& 0.18 & n.a. \\
& 0.11 & n.a. \\
& 1.47 & n.a. \\
$710-850$ & 0.46 & n.a. \\
$1000-1180$ & 0.05 & n.a. \\
& 0.29 & 0.33 \\
& 0.28 & 0.31 \\
& 0.26 & 0.34 \\
\hline
\end{tabular}

detects the transit of bright clusters of particles even if it likely fails to identify the arrival of the first beads of small diameters. It is also observed peak intensity values in Fig. 9b are lower than peak values in Fig. 9a. Higher index values in Fig. $9 \mathrm{~b}$ are more likely to pertain to isolated particles flowing through the region of interest as anticipated from the supervised analysis. Finally, particles of intermediate sizes are not detected by the index.

The unsupervised image analysis described in Sect. 2.3 is implemented on each of the ten experimental repetitions recorded for the studied diameters to automatically obtain particle travel time. Only the green channel of the images is analyzed and frames are preliminarily cropped to restrict particle search to the portion of the image depicting the rill bed.

Experimental videos fulfilling the constraints imposed through the fitting procedure are reported in Table 3. Specifically, two videos are fitted for the $75-90 \mu \mathrm{m}$, five for the 150 $180 \mu \mathrm{m}$, one for the $710-850 \mu \mathrm{m}$, and three for the 1000 $1180 \mu \mathrm{m}$ diameters. Travel time is estimated from the frame 
order number corresponding to the first value of $G$ in the fitted window and velocities relative to each fitting are presented in Table 3.

Results in Table 3 show that unfeasible velocities are obtained for the smaller particles and therefore confirm that the index is not able to detect first arrivals for beads of diameters of $150-180 \mu \mathrm{m}$ and smaller. Nonetheless, the fitting procedure can be used to sense the transit of particle clouds of small dimensions. Notably, four experiments out of the five reported in Table 3 for $150-180 \mu \mathrm{m}$ diameters pertain to the actual transit of the beads, whereas the velocity value equal to $1.47 \mathrm{~m} \mathrm{~s}^{-1}$ is biased by reflections on the water surface. On the other hand, larger particles, such as the $1000-1180 \mu \mathrm{m}$ beads, are easier to detect and estimated velocities are comparable to values obtained from visual analysis and experiments with rhodamine. This finding is also confirmed from analysis of Fig. 9. Indeed, the group of $75-90 \mu \mathrm{m}$ beads in Fig. 9a is likely not the first cluster of particles to arrive at the detection apparatus since the peak only occurs $37 \mathrm{~s}$ after sample deployment, thus yielding an equivalent yet unfeasible, flow velocity of $0.11 \mathrm{~m} \mathrm{~s}^{-1}$. Conversely, Fig. $9 \mathrm{~b}$ captures the whole transit of the particles as higher values of the index are measured for approximately 3-4 s. It is further observed that larger fitted windows correspond to larger diameters due to the fact that particle samples of larger dimensions tend to diffuse in the rill and, therefore, bead trains take longer times to cross the region captured by the camera.

As evidenced by the supervised and unsupervised analysis, the $1000-1180 \mu \mathrm{m}$ beads can be identified as the optimal particles to be adopted for the experimental settings of this study. In particular, velocities obtained from the automatic procedure are only $15 \%$ lower than estimates from visual analysis and results from both methodologies are close to the velocity estimated with the rhodamine dye. Promising results are also found for four out of ten experiments with the 150 $180 \mu \mathrm{m}$ beads, see Table 3. Specifically, the index is able to capture the passage of groups of particles of such small diameters for half of the experiments.

\section{Discussion}

Experimental findings demonstrate remarkable challenges in detecting the particles. Specifically, bead groups tend to dismember once deployed in the rill due to an array of concurring factors. Most importantly, the complex structure and morphology of the rill bed and the presence of severe sediment loads are relevant causes of particle dispersal. After an initial phase when runoff mainly occurs in the form of sheetflow on the soil surface, the onset of rilling develops through a supercritical flow velocity regime (Tatard et al., 2008). This condition produces the formation of small hydraulic jumps and pools where sediments are massively transported from higher-gradient regions, that is, the top of the hillslope plot, to downstream tracts. The rill evolves towards a small scale step-and-pool microchannel where velocity alternates from placid zones to faster reaches. In such settings, samples floating in the rill tend to remain trapped in pool sections. Isolated beads are then gradually released from the pools. This phenomenon tends to affect mostly the visibility of particles of smaller diameters which are harder to see in small quantities.

Despite such adverse environmental conditions, results support the feasibility of using fluorescent particles for environmental applications. In particular, the strengths of the methodology can be summarized as follows: (i) particles as small as $75 \mu \mathrm{m}$ are detected through both supervised and unsupervised procedures; (ii) reliable velocity estimates are obtained for the largest sizes, that is, $1000-1180 \mu \mathrm{m}$; and (iii) particle transits are successfully captured by an ad-hoc introduced index computed on the videos for most of larger diameters and for the 150-180 $\mu \mathrm{m}$ beads.

Interestingly, velocity estimates for the $1000-1180 \mu \mathrm{m}$ particles are in good agreement with measurements taken with rhodamine dye and are comparable to visual inspection analysis. Such promising results suggest that the beads allow for experimenting with longer flow paths as compared to tests performed with rhodamine WT. In particular, adsorption losses (Finkner and Gilley, 1986) and the presence of more advanced deployment and detection systems constitute serious limitations (Tatard et al., 2008) to large scale implementation of dyes. Further, particle transits are successfully captured by the index for the 1000-1180 $\mu \mathrm{m}$ and $150-180 \mu \mathrm{m}$ beads, thus suggesting that this diameter can be successfully used for tracing flows in small rills, provided the visibility of the particles is improved. Therefore, improving on the experimental apparatus and exploring alternative fluorophores to further enhance the visibility of the beads may significantly help the bead detection through the fitting procedure.

On the other hand, the preliminary proof-of-concept experiment has allowed to identify limitations of the proposed instrumentation that will be objective of future studies. In particular, results are affected by the limited visibility of the beads which is, in turn, influenced by the illumination conditions and by the meagre quantity of deployed material, that is, only $4-5 \mathrm{~g}$. With regards to image quality, the synthesis of highly fluorescent beads may be particularly beneficial. In addition, investigation of more biocompatible and biodegradable materials may allow for increasing the amount of tracer.

\section{Conclusions}

In this paper, a novel fluorescent particle tracer has been used to perform a proof of concept experiment to estimate overland flow velocity on a hillslope plot. Experiments have been performed to evaluate the accuracy and efficiency of the tracing methodology under the following adverse conditions: (i) high turbidity loads; (ii) interaction of the particles with soil sediments; and (iii) interaction of rain drops with the flow. 
Particles have been identified while flowing in the rill underneath a detection apparatus comprising light source and video acquisition units. Experimental results have demonstrated the feasibility of using the particles for environmental applications and have led to the identification of optimal diameters, namely, 1000-1180 $\mu \mathrm{m}$, for flow measurements in the described hillslope plot.

Future ameliorations to the illustrated methodology will encompass the design of enhanced biodegradable particle tracers and of the hardware components of the detection apparatus. Specifically, the following research directions will be pursued: (i) new biocompatible, biodegradable, and low cost fluorescent particles will be fabricated and laboratory and field tests will be performed to assess their performance. Such particles will be deployed in larger amounts in the environment, thus facilitating their detection through the unsupervised procedure; (ii) different fluorophores will be experimented with to guarantee fluorescence excitation for broad range of wavelengths. This amelioration will allow for enhancing bead visibility, using more portable lamps, and reducing total costs; (iii) miniature cameras will be tested to mitigate the illumination problem. Specifically, cameras will be located below the lamp unit in the particle detection apparatus, thus reducing the negative effects of light reflections; (iv) extensive field campaigns will be planned to quantify the uncertainty of the observations, provide a more extensive validation of presented results, and fully automate the detection procedure.

Acknowledgements. This work was partially supported by the MIUR Project PRIN 2009 N. 2009CA4A4A "Studio di un tracciante innovativo per le applicazioni idrologiche", by the National Science Foundation under Grant Nos. CMMI-0745753 and CMMI0926791, and by the Honors Center of Italian Universities (H2CU Sapienza Università di Roma). The authors would like to greatly thank G. Ubertini for conducting the granulometry analysis and R. Rapiti, G. Cipollari, I. Capocci, G. Mocio, and C. Pagano for the realization of the experimental apparatus and help with the experiments.

Edited by: N. Romano

\section{References}

Armand, R., Bockstaller, C., Auzet, A.-V., and Van Dijk, P.: Runoff generation related to intra-field soil surface characteristics variability: Application to conservation tillage context, Soil Till. Res., 102, 27-37, 2009.

Berger, C., Schulze, M., Rieke-Zapp, D., and Schlunegger, F.: Rill development and soil erosion: a laboratory study of slope and rainfall intensity, Earth Surf. Proc. Land., 35, 1456-1467, 2010.

Berman, E. S. F., Gupta, M., Gabrielli, C., Garland, T., and McDonnell, J. J.: High-frequency field-deployable isotope analyzer for hydrological applications, Water Resour. Res., 45, W10201, doi:10.1029/2009WR008265, 2009.
Budai, P. and Clement, A.: Refinement of national-scale heavy metal load estimations in road runoff based on field measurements, Transport. Res. D-Tr. E., 16, 244-250, 2011.

Domingo, F., Villagarcía, L., Boer, M. M., Alados-Arboledas, L., and Puigdefábregas, J.: Evaluating the long-term water balance of arid zone stream bed vegetation using evapotranspiration modelling and hillslope runoff measurements, J. Hydrol., 243, 17-30, 2001.

Doody, D. G., Higgins, A., Matthews, D., Foy, R. H., Pilatova, K., Duffy, O., and Watson, C. J.: Overland flow initiation from a drumlin grassland hillslope, Soil Use Manage., 26, 286-298, 2010.

Dunjó, G., Pardini, G., and Gispert, M.: The role of land use-land cover on runoff generation and sediment yield at a microplot scale, in a small Mediterranean catchment, J. Arid Environ., 57, 99-116, 2004

Dunkerley, L. D.: Estimating the mean speed of laminar overland flow using dye injection-uncertainty on rough surfaces, Earth Surf. Proc. Land., 26, 363-374, 2001.

Dunkerley, L. D.: An optical tachometer for short-path measurement of flow speeds in shallow overland flows: improved alternative to dye timing, Earth Surf. Proc. Land., 28, 777-786, 2003.

Esteves, M., Planchon, O., Lapetite, J. M., Silvera, N., and Cadet, P.: The "Emire" large rainfall simulator: design and field testing, Earth Surf. Proc. Land., 25, 681-690, 2000.

Fiener, P. and Auerswald, K.: Measurement and modeling of concentrated runoff in grassed waterways, J. Hydrol., 301, 198-215, 2005.

Finkner, S. C. and Gilley, J. E.: Sediment and dye concentration effects on fluorescence, Appl. Eng. Agric., 2, 104-107, 1986.

Ghahramani, A., Ishikawa, Y., Gomi, T., Shiraki, K., and Miyata, S.: Effect of ground cover on splash and sheetwash erosion over a steep forested hillslope: A plot-scale study, CATENA, 85, 34 47, 2011.

Gomi, T., Sidle, R. C., Miyata, S., Kosugi, K., and Onda, Y.: Dynamic runoff connectivity of overland flow on steep forested hillslopes: Scale effects and runoff transfer, Water Resour. Res., 44, W08411, doi:10.1029/2007WR005894, 2008a.

Gomi, T., Sidle, R. C., Ueno, M., Miyata, S., and Kosugi, K.: Characteristics of overland flow generation on steep forested hillslopes of central Japan, J. Hydrol., 361, 275-290, 2008b.

Gonzalez, R. C., Woods, R. E., and Eddins, S. L.: Digital Image Processing using MATLAB, Pearson Prentice-Hall, Upper Saddle River, NJ, 2004.

Haralick, R. M., Sternberg, S. R., and Zhuang, X.: Image analysis using mathematical morphology, IEEE T. Pattern. Anal., PAMI9, 532-550, 1987.

Hopp, L. and McDonnell, J. J.: Connectivity at the hillslope scale: Identifying interactions between storm size, bedrock permeability, slope angle and soil depth, J. Hydrol., 376, 378-391, 2009.

Hudson, J. A.: The impact of sediment on open channel flow measurement in selected UK experimental basins, Flow Meas. Instrum., 15, 49-58, 2004.

Hussein, M. H., Kariem, T. H., and Othman, A. K.: Predicting soil erodibility in northern Iraq using natural runoff plot data, Soil Till. Res., 94, 220-228, 2007.

Jodeau, M., Hauet, A., Paquier, A., Le Coz, J., and Dramais, G.: Application and evaluation of LS-PIV technique for the monitoring of river surface velocities in high flow conditions, Flow Meas. 
Instrum., 19, 117-127, 2008.

Johnson, A. C., Haria, A. H., Bhardwaj, C. L., Williams, R. J., and Walker, A.: Preferential flow pathways and their capacity to transport isoproturon in a structured clay soil, Pestic. Sci., 48, 225-237, 1996.

Jost, G., Schume, H., Hager, H., Markart, G., and Kohl, B.: A hillslope scale comparison of tree species influence on soil moisture dynamics and runoff processes during intense rainfall, J. Hydrol., 420-421, 112-124, 2012.

Laloy, E. and Bielders, C. L.: Plot scale continuous modelling of runoff in a maize cropping system with dynamic soil surface properties, J. Hydrol., 349, 455-469, 2008.

Lange, J., Greenbaum, N., Husary, S., Timmer, J., Leibundgut, C., and Schick, A. P.: Tracers for runoff generation studies in a Mediterranean region: comparison of different scales, in: Hydrology of the Mediterranean and Semiarid Regions, edited by: Servat, E., Najem, W., Leduc, C., and Shakeel, A., 278, 117-123, IAHS, Montpellier, France, 2003.

LeCoz, J., Hauet, A., Pierrefeu, G., Dramais, G., and Camenen, B.: Performance of image-based velocimetry (LSPIV) applied to flash-flood discharge measurements in Mediterranean rivers, J. Hydrol., 394, 42-52, 2010.

Lee, M. C., Lai, C. J., Leu, J. M., Plant, W. J., Keller, W. C., and Hayes, K.: Non-contact flood discharge measurements using an X-band pulse radar (I) Theory, Flow Meas. Instrum., 13, 265270,2002

Legout, C., Darboux, F., Nédélec, Y., Hauet, A., Esteves, M., Renaux, B., Denis, H., and Cordier, S.: High spatial resolution mapping of surface velocities and depths for shallow overland flow, Earth Surf. Proc. Land., 37, 984-993, 2012.

Léonard, J., Ancelin, O., Ludwig, B., and Richard, G.: Analysis of the dynamics of soil infiltrability of agricultural soils from continuous rainfall-runoff measurements on small plots, J. Hydrol., 326, 122-134, 2006.

Li, G.: Preliminary study of the interference of surface objects and rainfall in overland flow resistance, CATENA, 78, 154-158, 2009

Mathys, N., Klotz, S., Esteves, M., Descroix, M., and Lapetite, J. M.: Runoff and erosion in the Black Marls of the French Alps: Observations and measurements at the plot scale, CATENA, 63, 261-281, 2005

Mayor, A. G., Bautista, S., and Bellot, J.: Scale-dependent variation in runoff and sediment yield in a semiarid Mediterranean catchment, J. Hydrol., 397, 128-135, 2011.

McGuire, K. J. and McDonnell, J. J.: Hydrological connectivity of hillslopes and streams: Characteristic time scales and nonlinearities, Water Resour. Res., 46, W10543, doi:10.1029/2010WR009341, 2010.

McGuire, K. J., Weiler, M., and McDonnell, J. J.: Integrating tracer experiments with modeling to assess runoff processes and water transit times, Adv. Water Resour., 30, 824-837, 2007.

McMillan, H., Tetzlaff, D., Clark, M., and Soulsby, C.: Do timevariable tracers aid the evaluation of hydrological model structure? A multimodel approach, Water Resour. Res., 48, W05501, doi:10.1029/2011WR011688, 2012.

Mügler, C., Planchon, O., Patin, J., Weill, S., Silvera, N., Richard, P., and Mouche, E.: Comparison of roughness models to simulate overland flow and tracer transport experiments under simulated rainfall at plot scale, J. Hydrol., 402, 25-40, 2011.
Muste, M., Fujita, I., and Hauet, A.: Large-scale particle image velocimetry for measurements in riverine environments, Water Resour. Res., 44, W00D19, doi:10.1029/2008WR006950, 2008.

Muste, M., Ho, H.-C., and Kim, D.: Considerations on direct stream flow measurements using video imagery: Outlook and research needs, J. Hydro-Environ. Res., 5, 289-300, 2011.

Patin, J., Mouche, E., Ribolzi, O., Chaplot, V., Sengtahevanghoung, O., Latsachak, K. O., Soulileuth, B., and Valentin, C.: Analysis of runoff production at the plot scale during a long-term survey of a small agricultural catchment in Lao PDR, J. Hydrol., 426-427, 79-92, 2012.

Pérez-Latorre, F. J., deCastro, L., and Delgado, A.: A comparison of two variable intensity rainfall simulators for runoff studies, Soil Till. Res., 107, 11-16, 2010.

Planchon, O., Silvera, N., Gimenez, R., Favis-Mortlock, D., Wainwright, J., Le Bissonnais, Y., and Govers, G.: An automated salttracing gauge for flow-velocity measurement, Earth Surf. Proc. Land., 30, 833-844, 2005.

Puleo, J. A., McKenna, T. E., Holland, K. T., and Calantoni, J.: Quantifying riverine surface currents from time sequences of thermal infrared imagery, Water Resour. Res., 48, W01527, doi:10.1029/2011WR010770, 2012.

Qu, L., Zhao, J., Zhao, X., Yan, L., Zhou, J., and Lei, T.: A mechanic-electronic sensor for automatic measurement of sediment-laden flow rate from erosion runoff plots, J. Hydrol., 342, 42-49, 2007.

Riley, S. J. and Hancock, F.: A rainfall simulator for hydrologic and erosion experiments on mines, with an example of its applications at Ranger Uranium Mine, Northern Territory, Australia, The Australiasian Institute of Mining and Metallurgy Proceedings, 1, 3-8, 1997.

Rosso, R., Rulli, M. C., and Bocchiola, D.: Transient catchment hydrology after wildfires in a Mediterranean basin: runoff, sediment and woody debris, Hydrol. Earth Syst. Sci., 11, 125-140, doi:10.5194/hess-11-125-2007, 2007.

Rulli, M. C., Bozzi, S., Spada, M., Bocchiola, D., and Rosso, R.: Rainfall simulations on a fire disturbed mediterranean area, J. Hydrol., 327, 323-338, 2006.

Sadeghi, S. H. R., Bashari Seghaleh, M., and Rangavar, A. S.: Plot sizes dependency of runoff and sediment yield estimates from a small watershed, CATENA, in press, 2012.

Scherrer, S., Naef, F., Faeh, A. O., and Cordery, I.: Formation of runoff at the hillslope scale during intense precipitation, Hydrol. Earth Syst. Sci., 11, 907-922, doi:10.5194/hess-11-907-2007, 2007.

Tatard, L., Planchon, O., Wainwright, J., Nord, G., Favis-Mortlock, D., Silvera, N., Ribolzi, O., Esteves, M., and Huang, C. H.: Measurement and modelling of high-resolution flow-velocity data under simulated rainfall on a low-slope sandy soil, J. Hydrol., 348, 1-12, 2008.

Tauro, F., Aureli, M., Porfiri, M., and Grimaldi, S.: Characterization of buoyant fluorescent particles for field observations of water flows, Sensors, 10, 11512-11529, 2010.

Tauro, F., Grimaldi, S., Petroselli, A., and Porfiri, M.: Fluorescent particle tracers in surface hydrology: a proof of concept in a natural stream, Water Resour. Res., 48, W06528, doi:10.1029/2011WR011610, 2012a.

Tauro, F., Pagano, C., Porfiri, M., and Grimaldi, S.: Tracing of shallow water flows through buoyant fluorescent particles, Flow 
Meas. Instrum., 26, 93-101, 2012b.

Ticehurst, J. L., Cresswell, H. P., McKenzie, N. J., and Glover, M. R.: Interpreting soil and topographic properties to conceptualise hillslope hydrology, Geoderma, 137, 279-292, 2007.

Uchida, T. and Asano, Y.: Spatial variability in the flowpath of hillslope runoff and streamflow in a meso-scale catchment, Hydrol. Process., 24, 2277-2286, 2010.
Vacca, A., Loddo, S., Ollesch, G., Puddu, R., Serra, G., Tomasi, D., and Aru, A.: Measurement of runoff and soil erosion in three areas under different land use in Sardinia (Italy), CATENA, 40, 69-92, 2000. 